\title{
Tattoos: A summary knowledge for the practising clinician
}

\author{
T Isaacs, MB ChB, MFamMed, FCDerm (SA), MMed; R M Ngwanya, MB ChB, FCDerm (SA); R J Lehloenya, BSc, MB ChB, FCDerm (SA)
}

Division of Dermatology, Department of Medicine, Groote Schuur Hospital and University of Cape Town, South Africa

Corresponding author: R J Lehloenya (rannakoe.lehloenya@uct.ac.za)

\begin{abstract}
Tattoos are becoming increasingly common. They have an impact on many aspects of clinician-patient interaction. Therefore, it is necessary for clinicians to have a basic knowledge of pertinent issues relating to tattoos. We provide a brief overview aimed at pointing the practising clinician who interacts with a tattooed person in the right direction. We discuss types of tattoos; their evolving epidemiology; the process of tattooing and variety of pigments used; medical application and relevance of tattoos; complications of tattooing; methods of removing tattoos, the efficacy of these methods and their associated complications; legislative framework guiding tattooing in South Africa and recent significant developments in the industry.
\end{abstract}

S Afr Med J 2018;108(9):714-720. DOI:10.7196/SAMJ.2018.v108i9.13231

Tattoos are not a symptom of a mental disturbance. Most of the tattooed have simple motives and explanations: 'because I like it', 'because I'm a tomboy', 'to remember'. They do not accept the interpretations that the researchers describe and impose. Actually, the act of tattooing is more sacred to the subjected than the tattoo itself. (Kazandjieva and Tsankov ${ }^{[1]}$ )

Tattoos are becoming increasingly common in all demographic groups globally and consequently so are clinician encounters with tattooed individuals. Tattoos have the potential to have an impact on clinicianpatient interaction, ultimately affecting clinical decision-making and patient outcomes. Tattoos may affect the clinician's first impression of the patient, their physical and psychological assessment, and thus their management of that patient. ${ }^{[2]}$ Furthermore, tattoos and their complications are often the primary reason for seeking medical help. Considering the high prevalence of tattoos, many clinicians do not have sufficient knowledge of tattoos and tattooing to make informed clinical decisions.

In this brief review, we provide practising clinicians with basic knowledge regarding tattoos to enable them to forge more functional clinician-patient relationships and to guide them in their daily practice.

\section{What is a tattoo?}

A tattoo refers to implantation of an exogenous pigment into the skin or mucous membranes.

\section{Types of tattoos}

Tattoos can be accidental or deliberate, permanent or temporary, professional or amateur, cosmetic, decorative or medical.

Accidental tattoos are also referred to as traumatic tattoos, and result from inoculation into a wound of substances such as asphalt, amalgam, graphite, ink or gun powder.

Permanent tattoos involve a colourfast pigment implanted below the dermo-epidermal junction and retained by macrophages and fibroblasts in the dermis.

Temporary tattoos resemble a permanent tattoo, but are painted or airbrushed or are a decal on the surface of the skin and usually last for a few days.

Professional tattoos are created by trained individuals at a tattoo parlour, usually with a tattoo machine. The pigment is mostly evenly dispersed in the dermis.
Amateur tattoos are often applied at home, using only a needle and one colour ink. Ink deposition tends to be more superficial and variable.

Cosmetic tattoos involve the use of pigment to enhance the appearance of body parts, resemble make-up or mask deformities. These include permanent make-up, tattoos over surgical scars and nipple tattoos after a mastectomy.

Medical tattoos are used to treat a medical condition, communicate medical information, or mark a body location for medical procedures or future review.

Invisible tattoos are also called UV or black-light tattoos and are made with dyes that fluoresce and glow visibly under ultraviolet light.

\section{History, evolution and epidemiology of tattoos}

Tattoos are as old as recorded human history, dating back $>5000$ years. Ötzi the Iceman, whose 5300 -year-old freeze-dried body was discovered in the Tyrolean Alps in 1991, was tattooed over his arthritic joints. ${ }^{[3]}$ The epidemiology of tattooing has evolved over time and represents changes in personal, cultural and political influences. Despite tattoos mainly being associated in recent history with prisoners, prostitutes and seamen, a number of prominent and respected leaders have adorned their bodies with tattoos, including Winston Churchill, his mother, Tsar Nicholas II, King George V, Thomas Edison and Theodore Roosevelt, and among current world leaders, Canadian Prime Minister Justin Trudeau. ${ }^{[4,5]}$ In the 1980s tattoos gained use as a means to protest against the conservative middle-class norms of society. In recent years, the popularity of tattoos has surged across cultures, geographical areas, social classes and levels of education - probably due to digital media and commercialisation of culture. ${ }^{[6]}$ An estimated 100 million Europeans have tattoos. ${ }^{[7]}$ A 2006 US study found a lifetime prevalence of $24 \%$, highest among males and younger people. ${ }^{[8]}$ A 2012 Australian study found a lifetime prevalence of $14.5 \%$, overall highest among men, but with the highest rates among women in their 20s. ${ }^{[2]}$ The two studies found a higher prevalence among those with a current or lifetime exposure to alcohol consumption, drug use, lower socioeconomic status, lower education level, multiple partners and prison experience. More recent studies show a change in demographics of tattooed individuals. A 2016 US study reported that tattoos are obtained by individuals with higher levels of education to remember a loved one or purely for 
enjoyment. ${ }^{[9]}$ In a 2017 German study, the mean age was 35 years, most were female, employed and with no history of drug or alcohol

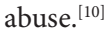

\section{Motivation for tattooing}

Understanding the individual motivation for obtaining a tattoo is helpful in addressing any tattoo-related health issues. ${ }^{[1]]}$ The reasons for tattooing differ among populations, societies, age groups and time points. In ancient times, tattoos were used for therapeutic purposes and as a system of knowledge transmission. ${ }^{[3,9,12]}$ Although religions such as Christianity and Judaism have historically taken an unfavourable view of tattoos, the latter continues to play a deep religious and cultural role in some societies as totems of devotion, power, magical abilities as well as providing identity and guidance in the afterlife. ${ }^{[13]}$ During recent years, motivations include personal symbolism, expression of shared values within a subculture, quest for individuality, enhancing attractiveness, rebellion, fashion, using the body as a canvas for art, peer pressure and impulsive tattooing under the influence of alcohol and drugs. ${ }^{[6,9,11,13-17]}$ The motivation also varies with social circumstances and education. ${ }^{[6,9,14]}$ Less than $10 \%$ of tattoos are now initiated under the influence of alcohol or drugs, and in this group those with only a high-school education are disproportionately represented. ${ }^{[9,14}$

\section{Methods of tattooing}

Apart from temporary tattoos, tattooing is an invasive procedure that permanently inoculates potentially hazardous chemicals into the body. Traditional and amateur tattooing involve rubbing of pigment into patterned cuts on the skin or hand-tapping the ink into the skin using sharp tools. Modern professional tattoos are performed with a tattoo machine, using a mechanised needle that inoculates the pigment into the skin in controlled quantities and patterns. The pigment is then dispersed in the epidermis and dermis. The epidermal pigment is eliminated via desquamation, while the dermal pigment is absorbed by macrophages and retained within fibroblasts. A network of connective tissue surrounds these ink-containing fibroblasts, entrapping and immobilising them.

\section{Pigments used in tattooing}

A wide spectrum of materials is used in tattoos. Most tattoos are black, comprising carbon, sometimes with shading additives such as titanium dioxide or iron oxides and excipients such as formulants, dispersants, preservatives and fragrances. Most modern tattoos contain organic pigments, including heavy metals, e.g. titanium, barium, aluminium and copper. Others include antimony, arsenic, cadmium, chromium, cobalt, lead, nickel contaminants and mercury sulphide. The inks used by professional tattooists vary in purity and may contain substances that have not been formally tested for human use. In a Swiss study, preservatives banned for use in cosmetics were found in up to $14 \%$ of 416 samples tested. Pigment used in amateur tattoos includes a variety of inks (India ink, pen ink), carbon particles originating from burnt wood, vegetable matter, cotton, plastic, shoe heels, styrofoam, paper and molten rubber mixed with water and sugar. Ash mixed with own urine, a practice believed to reduce the chance of infection in prisons, has also been used.

\section{Henna tattoos}

The colouring properties of henna (Lawsonia inermis) have been known for centuries. ${ }^{[18,19]}$ Temporary henna tattoos are now common practice across the globe. While natural henna has a very low allergic potential, colouring agents added to natural henna can cause hypersensitivity reactions. The additives include paraphenylenediamine (PPD), coffee, black tea, lemon juice, eucalyptus, clove, mustard oil, fresh urine of animals, fenugreek seeds, okra and tamarind. ${ }^{[19]}$ Sensitisation to henna tattoos is estimated to occur in at least $2.5 \%$ of exposed persons. ${ }^{[20]}$ Hypersensitivity reactions have been reported 4 - 20 days after first exposure ${ }^{[19]}$ Almost $90 \%$ of those sensitised show a positive patch test to PPD. Immediate reactions to PPD are rare, unless there was prior exposure and sensitisation to PPD or cross-reactivity with related compounds that have an amino group in the para-position of the benzene ring, e.g. paraaminobenzoic acid in sunscreens, sulphonamides, sulfonylureas, azo dyes, local anaesthetics and para-aminosalicylic acid. ${ }^{[20-22]}$ Henna tattoos should be avoided in small children and in persons with glucose-6-phosphate dehydrogenase (G6PD) deficiency, as henna is a potent oxidant of G6PD-deficient cells. This can result in life-threatening haemolysis. ${ }^{[23]}$ Other rare complications of henna application are hypertrichosis, depigmentation, abscess formation, severe oedema and renal failure. ${ }^{[20]}$

\section{Medical applications of tattoos}

Application of tattoos for medical reasons is widespread and dates as far back as 3300 BC. $^{[24]}$ These include positional tattoos as reference points for radiation therapy; nipple-areola complex reconstruction after breast cancer or reduction; endoscopic tattooing for surveillance; camouflage for corneal injury, burns, surgical or traumatic hypochromic scars or vitiligo; dermatography for portwine stains; scarring or persistent alopecia; after hair restoration procedures and brow-lift surgery; and lip contouring and colour change. ${ }^{[16,25,26]}$ Tattoos have also been used as a form of medical alert identification during emergency situations, although this is discouraged in minors and often not trusted by physicians. ${ }^{[25,27,28]}$ In forensic pathology, tattoos are increasingly being used to identify and collate personal history of deceased individuals. ${ }^{[29,30]}$

\section{Natural history}

A common problem with tattoos is fading over time of inkladen macrophages deeper into the dermis owing to migration. Spontaneous degradation of dyes also occurs in the skin, the reverse of which is seen in immediate tattoo darkening on exposure to lasers. Photodegradable dyes, dilution with local anaesthetic and superficial inoculation of dyes predispose to fading. ${ }^{[31]}$ Sagging associated with ageing and stretching of the skin as seen in pregnancy, growth spurts or body building result in distortion of the tattoo.

\section{Complications of tattoos}

Serup et al..$^{[7]}$ recently proposed classifying tattoo complications as primary infections, non-infectious inflammatory (allergic, nonallergic, urticaria), psychosocial, technique and treatment related and miscellaneous. The complications can be acute, delayed or chronic. Coloured tattoos, especially red tattoos, are $>6$ times likely to lead to complications than black tattoos (Fig. 1). Approximately $70 \%$ of tattoo complications are confined to the skin, $7 \%$ are systemic and $6 \%$ are persistent. ${ }^{[7]}$

\section{Infectious complications}

Poor procedural and personal hygiene contribute to infectious complications. Bacteria, viruses and fungi can complicate tattoos.

Bacterial infections can be superficial or deep skin infections. Impetigo and ecthyma tend to occur in the first few days after tattooing at the tattoo site, and are caused by unsterile instruments. If untreated, these may progress to cellulitis, gangrene and sepsis. 
Inoculation of mycobacterium organisms, including tuberculosis, into the skin, has been reported. ${ }^{[7,32,33]}$

Viruses are a complication. Transmission of viral hepatitis is a major infective complication. Tattoos are the third most common means of transmission of hepatitis B and are an independent risk factor for the transmission of hepatitis C. The risk is higher with amateur tattoos. Transmission of HIV also remains a risk. ${ }^{[34]}$ However, in developed countries with a lower prevalence of viral hepatitis and more strict regulations regarding tattoo parlours, the risk is no different than that in the general population. ${ }^{[35]}$

Fungal infections occurring after tattooing are rare.

Inflammatory reactions consist predominantly of hypersensitivity reactions to different dyes. The most important colours that lead to complications, in order of frequency, are red, black, green and multicoloured. Hypersensitivity reactions can be classified as urticarial, lichenoid, eczematous, pseudolymphomatous and granulomatous. Clinically, these reactions present as plaques, ulceration and hyperkeratosis - often with pruritus. ${ }^{[7]}$ The absence of reliable methods to predict the development of hypersensitivity reactions poses a challenge. Patch tests have been shown to have a poor predictive value, as the hypersensitivity reactions against tattoos develop slowly and are unlikely to be caused by an allergen directly present in the tattoo ink; rather by a metabolite. ${ }^{[36]}$ Testing of small areas when planning to use high-risk dyes may reduce the risk of hypersensitivity reactions. ${ }^{[37]}$ Conditions such as sarcoidosis, psoriasis, lichen planus, vitiligo and discoid lupus can also localise to tattoo sites (Fig. 2). ${ }^{[38]}$ Black tattoos with papulonodular lesions may be suspicious of sarcoidosis. ${ }^{[39]}$

\section{Psychosocial complications}

There is good evidence that supports having a tattoo as proxy for deviant social behaviour, being perceived negatively, victimisation by authorities and a higher risk of early death. ${ }^{[40-49]}$ These associations are declining as a result of the changing demographics of the tattooed population, and based on current evidence should be regarded as an epiphenomenon rather than a causal one. ${ }^{[44,50]}$

\section{Miscellaneous complications}

The presence of tattoos has an effect on clinical assessment, diagnostic tools and treatment modalities of many conditions. In burns, tattoos affect the histology, use of diagnostic dyes, laser Doppler imaging and magnetic resonance imaging (MRI). ${ }^{[51-56]}$

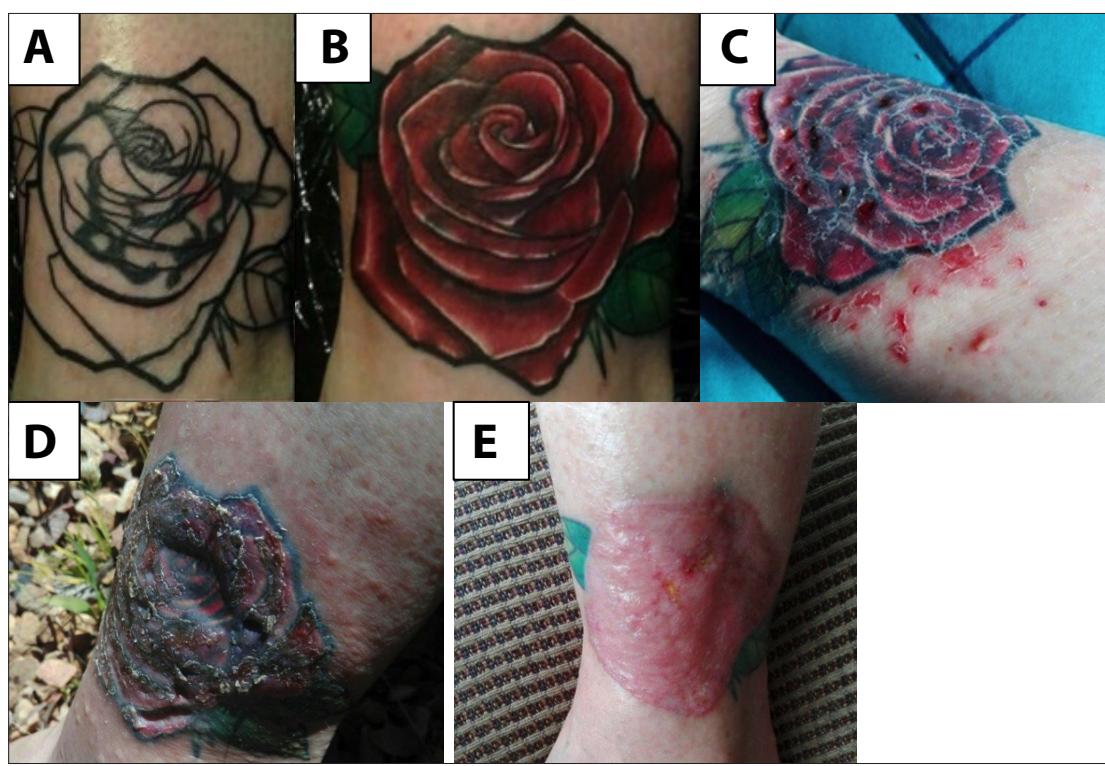

Fig. 1. (A) Original black ink tattoo outline. (B) Completed tattoo. (C) Early reaction to the red ink in the tattoo. (D) Late reaction in the tattoo, showing loss of dermal volume. (E) Final outcome of surgical excision and skin graft.

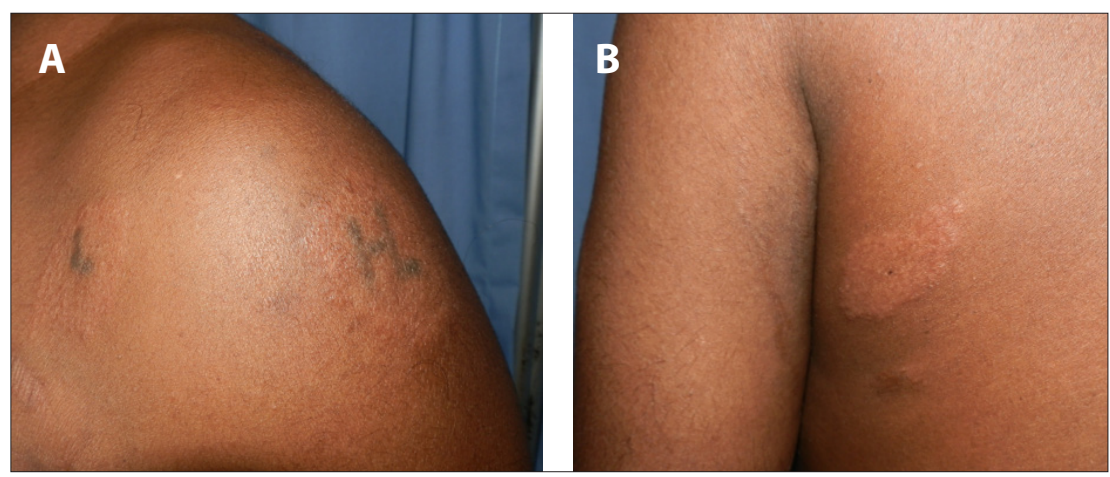

Fig. 2. Sarcoid (sarcoidal granulomas on histology) that developed first (A) on tattooed areas, and then (B) on normal skin in a patient with pulmonary sarcoidosis.

The effect of the end-products of burnt dyes on the progression and healing of the skin is unknown. Tattoos are known to cause blisters during the use of low-light therapy for neuromuscular pain. ${ }^{[57]}$ Lasers cleave some dyes into toxic and carcinogenic substances. ${ }^{[58,59]}$ However, there are limited data on the systemic effects of tattoo pigments or their metabolites after burns. ${ }^{[61]}$ The effect of tattoos on other light-based therapies, such as phototherapy, with or without a photosensitiser, is unclear. Similarly, their impact on diagnostic tools such as dermoscopy and mole mapping still needs clarification. Spinal tap, epidural anaesthesia, vascular access for haemodialysis and other procedures could pose a problem in patients with tattoos in areas used for these techniques. ${ }^{[2]}$ A review of the literature failed to identify any risk associated with epidural anaesthetics in patients with lower-back tattoos, but tissue transport to deeper tissues was confirmed. ${ }^{[63]}$
Tattoo pigment can migrate to the lymph nodes draining the tattooed area and have also been found in other internal organs including the liver, presumably via haematogenous spread. ${ }^{[64]}$ Lymph node infiltration by tattoo ink has to be taken into consideration when histologically assessing any lymph node, especially sentinel lymph nodes. ${ }^{[64-66]}$ Other rarer complications of tattooed skin include generation of less sweat with higher sodium concentration; hypertrichosis; photosensitivity to red, yellow black and blue dyes; milia; keloids; and Koebner phenomenon. ${ }^{[15,67,68]}$

\section{Cancer and tattoos}

An extensive review of the published literature reported only 50 cases of skin cancer possibly associated with tattoos. Considering global exposure to tattooing, this low association has to be regarded as coincidental. ${ }^{[69,70]}$ However, there are considerable diagnostic challenges in detecting skin cancer within tattoos. ${ }^{[72]}$ 


\section{Histological features of tattoos}

The basic histopathological feature of uncomplicated tattoos is the presence of free pigment in the dermis and/or within perivascular macrophages. The pigment should be differentiated from melanin; chrysiasis; ochronosis; and tetracycline, antimalarial and amiodarone hyperpigmentation. In complicated tattoos, the histopathological features are variable, often correlating with the clinical presentation, and are best grouped under inflammatory reaction patterns. ${ }^{[72,73]}$ These are

Interface patterns, in which lichenoid reactions are the most common, may be indistinguishable from lichen planus and tend to be associated with a reaction to red ink.

Psoriasiform patterns include psoriasis developing within a tattoo and Koebner phenomenon.

Spongiotic reactions are due to a delayed type IV hypersensitivity reaction and clinically manifest as eczema.

Vesicobullous lesions occur in the context of a severe allergic contact dermatitis.

Pseudo-epitheliomatous lesions can mimic squamous cell carcinoma and keratoacanthomas.

Granulomatous forms are associated with tattoo reactions, including tuberculoid, sarcoidal, suppurative and palisading lesions. Tuberculosis, other mycobacterial and deep fungal infections should be excluded by means of special stains and culture techniques in cases of granulomatous and pseudo-epitheliomatous reaction patterns.

Fibrosing caused by morphea- and scleroderma-like reactions are limited to red ink tattoos.

Vasculitic reactions are rare.

\section{Removal of tattoos}

The two most common reasons for seeking tattoo removal are personal reasons and complications. Personal reasons include change in relationship status, religious reasons, past drug addiction or gang membership, dissatisfaction and boredom with the tattoo. Desire for re-integration into society, particularly by rehabilitated prisoners and gang members with tattoos, is an under-recognised challenge. Professional and social pressures seem to be a less common motivation in recent studies - more so than in older ones. ${ }^{[74-77]}$ The motivation to remove a tattoo is usually more considered than the initial tattoo. ${ }^{[75]} \mathrm{A}$ US study of urban patients found that $>70 \%$ were not worried about health risks of tattoo removal. ${ }^{[9]}$ A subset of patients seek complete surgical removal of the tattoo, refusing other removal methods, despite the higher risk of scarring. They tend to have a deeper emotional state associated with the tattoo itself and the motivation(s) for which it was done. ${ }^{[76]}$ Tattoos that lead to complications are associated with sustained reduction in quality of life, necessitating removal. ${ }^{[78]}$ The challenge is to ensure that the outcomes of the intervention are an improvement on the initial complication. Tattoo removal techniques involve the destruction of the outer layers of the skin by mechanical, chemical or thermal methods. Temporary camouflaging is a less invasive option. ${ }^{[80]}$

\section{Mechanical tattoo removal}

Mechanical methods are more cost-effective and less time-consuming than thermal methods. ${ }^{[80]}$ These include:

Salabrasion involves abrading the superficial dermis with coarse granules of salt and a moist gauze pad or sponge. The salt is left on the skin surface under an occlusive dressing for 24 hours. Modified techniques include immediate removal of the salt, with resultant reduced scarring and hypopigmentation, and prior dermabrasion of the epidermis. ${ }^{[80,81]}$ Salabrasion is an effective method for removal of amateur tattoos but because of the associated risk of scarring, is now rarely used. ${ }^{[80]}$

Dermabrasion involves abrading the skin with a rapidly spinning diamond fraise wheel or a wire brush. ${ }^{[83]}$ Amateur tattoos often require a single treatment, while deeper professional ones require multiple treatments. Dermabrasion has also been used in conjunction with surgical removal. ${ }^{[80]}$ Complications include hypertrophic scarring and dyspigmentation.

Surgical excision can completely remove small tattoos in a single procedure. Larger tattoos may require multiple procedures with staged excisions and may be associated with a greater risk of complications. Options include punch biopsy excision for very small tattoos, elliptical excision in areas with sufficient skin laxity, O-to-Z flap for ovoid lesions, rotation flaps for elongated tattoos and skin grafts in areas of decreased skin laxity. ${ }^{[83-85]}$ Split thickness tangential excision using a dermatome and healing by secondary intention has the advantage of being relatively inexpensive, the depth of skin removal can be accurately controlled, there is no donor site and scarring is minimal. ${ }^{[86,87]} \mathrm{A}$ modified method of tangential excision followed by dermal overgrafting has also been used. ${ }^{[89]}$ Surgery may result in distortion of the normal anatomy, resulting in a less acceptable cosmetic outcome than the tattoo itself. ${ }^{[80]}$

\section{Chemical tattoo removal}

Imiquimod is a topical immunomodulator used in the treatment of non-melanoma skin cancers. In animal models, 5\% imiquimod cream for 7 days successfully removed acute-phase tattoos. In humans, two randomised controlled trials of $5 \%$ imiquimod cream as an adjunct to laser therapy failed to show significant benefit and the combination with imiquimod was associated with a significantly higher risk of adverse events. ${ }^{[00]}$

Ingenol mebutate is a US Food and Drug Administrationapproved topical treatment for actinic keratosis. Two applications of $0.1 \%$ ingenol mebutate gel consistently removed 2-week-old tattoos from hairless mice. The skin healed within 20 days, resulting in mild scarring. ${ }^{[91]}$ There are ongoing studies on the use of ingenol mebutate to remove tattoos in humans.

\section{Thermal tattoo removal}

Lasers have been used to remove tattoos since the 1960s and are now the treatment modality of choice. ${ }^{[91,92]}$ Non-selective destructive argon and carbon dioxide laser therapy has been superseded by advanced laser technologies that rely on the concept of selective photothermolysis. ${ }^{[94]}$ These produce preferential and minimal injury to pigment-containing structures by using wavelengths that provide selective absorption and pulse duration less than or equal to the time taken for the heat to dissipate from the target tissue to surrounding structures. Q-switched lasers include the Q-switched ruby laser $(694 \mathrm{~nm})$, Q-switched neodymium-doped yttrium-aluminum-garnet (Nd:YAG) (532 nm and $1064 \mathrm{~nm}$ ) and Q-switched alexandrite laser $(755 \mathrm{~nm})$. They deliver ultra-short pulses in the nanosecond domain, with minimal side-effects. Effective tattoo removal requires the use of the appropriate wavelength that is selectively absorbed by the ink in the tattoo.

Q-switched ruby emits red light, which is effectively absorbed by black and green inks, but other colours are less efficiently treated. Transient dyspigmentation and rarely depigmentation are described, but hypertrophic scarring is not seen. ${ }^{[94-96]}$ Q-switched ruby is more effective at removing amateur than professional tattoos. ${ }^{[96]}$

Q-switched Nd:YAG laser (1 $064 \mathbf{~ n m}$ ) effectively removes black tattoo ink, but removes other colours less efficiently. ${ }^{[98]}$ It is an excellent choice for removal of tattoo pigment in darkly pigmented skin. ${ }^{[99]}$ 
Table 1. Summary of tattoo colours, composite pigment, best laser treatment and possible complications

\begin{tabular}{|c|c|c|c|}
\hline Colour & Tattoo pigment & Appropriate laser & Complications \\
\hline Black & India ink, carbon, iron oxide & $\begin{array}{l}\text { QS ruby, QS alexandrite, } \\
\text { QS Nd:YAG } 1064 \mathrm{~nm}\end{array}$ & Hypopigmentation, depigmentation \\
\hline Blue & Cobalt aluminate & $\begin{array}{l}\text { QS ruby, QS alexandrite, } \\
\text { QS Nd:YAG } 1064 \mathrm{~nm}\end{array}$ & Hypopigmentation \\
\hline Red & $\begin{array}{l}\text { Mercury sulphide, cadmium } \\
\text { selenide, sienna, azo dyes }\end{array}$ & $\begin{array}{l}\text { QS Nd:YAG } 532 \mathrm{~nm} \text {, pulsed dye, } \\
\text { alexandrite } 510 \mathrm{~nm}\end{array}$ & $\begin{array}{l}\text { Hypopigmentation, tattoo ink darkening, } \\
\text { hypersensitivity reactions }\end{array}$ \\
\hline Yellow & $\begin{array}{l}\text { Ochre, cadmium, curcumin } \\
\text { yellow }\end{array}$ & QS Nd:YAG 532 nm & Hypopigmentation, tattoo ink darkening \\
\hline Brown & Ochre & $\begin{array}{l}\text { QS ruby, QS alexandrite, } \\
\text { QS Nd:YAG } 1064 \mathrm{~nm}\end{array}$ & Hypopigmentation, tattoo ink darkening \\
\hline Green & $\begin{array}{l}\text { Chromium oxide, malachite } \\
\text { green, lead chromate }\end{array}$ & QS ruby, QS alexandrite & Hypopigmentation, hypersensitivity reactions \\
\hline White & Titanium dioxide, zinc oxide & QS Nd:YAG 532 nm & Hypopigmentation, tattoo ink darkening \\
\hline Skin-coloured & - & QS Nd:YAG $532 \mathrm{~nm}$ & Hypopigmentation, tattoo ink darkening \\
\hline
\end{tabular}

The deeper penetration allows less absorption by melanin; hence, pigmentary changes are less frequent than with QSR.

Q-switched Nd:YAG laser $(\mathbf{5 3 2} \mathbf{~} \mathbf{~ m})$ is effective at treating red and yellow pigments. ${ }^{[95]}$

Q-switched alexandrite laser $(755 \mathrm{~nm})$ effectively removes multicoloured professional and amateur tattoos, with minimal side-effects. It is also effective at eliminating traumatic, cosmetic and amalgam tattoos. ${ }^{[99-101]}$

Pulsed dye alexandrite laser $(\mathbf{5 1 0} \mathbf{~ n m})$ successfully removes red tattoo pigment. $^{[103]}$

Tattoo colours, their composite pigment, best laser treatment and possible complications are summarised in Table 1. Other complications of laser tattoo removal include systemic allergic or localised granulomatous tissue reactions, ignition of explosive particles in traumatic tattoos and atrophic scars. The use of lasers for tattoo removal by untrained staff without an understanding of the basic principles of the procedures poses another challenge. This results in an unnecessarily high rate of undesirable sequelae. ${ }^{[46,103]}$ The preferred methods of tattoo removal are costly and as a result many people resort to medical laymen. The crude methods used by laymen range from salabrasion or wire brush abrasion, burns (heated iron rods or cigarettes), chemical burns (high concentration phenol, trichloroacetic acid or glycolic acid) to a range of creams. These methods generally have poorer outcomes. ${ }^{[46,104]}$ Tattoo removal with phenol can be fatal. ${ }^{[105]}$

\section{Donating blood and tattoos}

Most countries have a temporary donor deferral policy for tattooed individuals. In South Africa (SA), prospective donors are deferred from donating blood for 6 months after having received a tattoo. ${ }^{[15,106]}$ Implementation of any deferral policy is dependent on donor compliance with disclosure of behaviour.

Regulatory framework in South Africa Tattooing is currently regulated in SA under the by-laws of medical waste management, as well as in some municipalities. ${ }^{[72]}$ The SA Council for Piercing and Tattoo Professionals (CPTP) is the regulating body established to regulate body artists in SA. There are currently guidelines for tattooing and tattoo parlours by CPTP, and the departments of Labour and Health are awaiting approval. ${ }^{[107]}$ To further improve outcomes, adequate informed consent; tattooist, tattoo parlour and ink certification; hygiene security and monitoring; documentation and reporting of complications and culprit inks are necessary and would help to establish a national surveillance system. ${ }^{[108]}$

\section{New developments in tattooing}

Internationally, new strategies are being developed to make tattoo removal safer and easier. Development of insoluble, bioresorbable pigments stabilised through micro-encapsulation provides dyes and pigments with defined toxicological properties, predictable biokinetics, chemical stability, as well as easier clearance with lasers. ${ }^{[36,109]}$

\section{Summary}

The practice of tattooing has become more widespread worldwide. It is important for clinicians to have a basic understanding of all aspects of tattooing to enable them to forge more functional clinician-patient relationships and provide better treatment options and referral for these patients.

\section{Acknowledgements. None.}

Author contributions. RJL: conceived the idea, reviewed the literature and wrote the manuscript; TI: reviewed the literature and wrote the manuscript; and RMN: reviewed the literature and wrote the manuscript. Funding. None.

Conflicts of interest. None.

1. Kazandjieva J, Tsankov N. Tattoos and piercings. Clin Dermatol 2007;25(4):361. https://doi. org/10.1016/j.clindermatol.2007.05.010

2. Heywood W, Patrick K, Smith AM, et al. Who gets tattoos? Demographic and behavioral correlates of ever being tattooed in a representative sample of men and women. Ann Epidemiol 2012;22(1):51-56. https.//doi.org/10.1016/j.annepidem.2011.10.005

3. Kean WF, Tocchio S, Kean M, Rainsford KD. The musculoskeletal abnormalities of the Similaun Iceman ('OTZI'): Clues to chronic pain and possible treatments. Inflammopharmacol 2013;21(1):11-20. https://doi.org/10.1007/s10787-012-0153-5

4. Davies R. Eleven historical figures who surprisingly had tattoos. 2015. https://www.tattoodo.com/ a/2015/11/11-historical-figures-who-surprisingly-had-tattoos/ (accessed 3 August 2018).

5. Barford V. Is Canada's new PM the only world leader with a tattoo? http://www.bbc.com/news magazine-34585178 (accessed 3 August 2018).

6. Wohlrab S, Stahl J, Kappeler PM. Modifying the body: Motivations for getting tattooed and pierced. Body Image 2007;4(1):87-95. https://doi.org/10.1016/j.bodyim.2006.12.001

Serup J, Sepehri M, Hutton Carlsen K. Classification of tattoo complications in a hospital material of 493 adverse events. Dermatology 2016;232(6):668-678. https://doi.org/10.1159/000452148

8. Laumann AE, Derick AJ. Tattoos and body piercings in the United States: A national data set. J Am Acad Dermatol 2006;55(3):413-421. https://doi.org/10.1016/j.jaad.2006.03.026

Dimitropoulos V, Brown CW, jun., Ressa NA, Newman M. Reasons behind the ink. Cutis 2016;98(5):320-322.

10. Muller CS, Oertel A, Korner R, Pfohler C, Vogt T. Socio-epidemiologic aspects and cutaneous side effects of permanent tattoos in Germany. Tattoos are not restricted to a specific social phenotype. Dermatoendocrinol 2017;(1):e1267080. https://doi.org/10.1080/19381980.2016.1267080

11. Nichols HFD. Embodied identities and positional choices: How tattooees construct identity and negotiate a tattooed status within society. Psychol Soc 2005;32:1-23.

12. Krutak L. The cultural heritage of tattooing: a brief history. Curr Probl Dermatol 2015;48:1-5. https:// doi.org/10.1159/000369174 
13. Scheinfeld N. Tattoos and religion. Clin Dermatol 2007;25(4):362-366. https://doi.org/10.1016/j. clindermatol.2007.05.009

14. Lande RG, Bahroo BA, Soumoff A. United States military service members and their tattoos: A descriptive study. Mil Med 2013;178(8):921-925. https://doi.org/10.7205/milmed-d-13-00131

15. Kluger N. Tattooing and psoriasis: Demographics, motivations and attitudes, complications, and impact on body image in a series of 90 Finnish patients. Acta Dermatovenerol Alp Pannonica Adriat 2017;26(2):29-32.

16. Saed S, Ibrahim O, Bergfeld WF. Hair camouflage: A comprehensive review. Int J Womens Dermatol 2017;3(1 Suppl):S75-S80. https://doi.org/10.1016/j.jiwd.2017.02.016

17. Shoham E. 'Signs of honor' among Russian inmates in Israel's prisons. Int J Offender Ther Comp Criminol 2010;54(6):984-1003. https://doi.org/10.1177/0306624X09344841

18. Raboobee N. Sensitisation from PPD in temporary henna tattoos and subsequent severe allergic contact dermatitis from hair dye. Curr Allergy Clin Immunol 2004;17:194-195.

19. Kazandjieva J, Grozdev I, Tsankov N. Temporary henna tattoos. Clin Dermatol 2007;25(4):383-387. https://doi.org/10.1016/j.clindermatol.2007.05.013

20. De Groot AC. Side-effects of henna and semi-permanent 'black henna' tattoos: A full review. Contact Dermatitis 2013;69(1):1-25. https://doi.org/10.1111/cod.12074

21. Arroyo MP. Black henna tattoo reaction in a person with sulfonamide and benzocaine drug allergies. J Am Acad Dermatol 2003;48(2):301-302. https://doi.org/10.1067/mjd.2003.56

22. Mukkanna KS, Stone NM, Ingram JR. Para-phenylenediamine allergy: Current perspectives on diagnosis and management. J Asthma Allergy 2017;10:9-15. https://doi.org/10.2147/JAA.S90265

23. Raupp P, Hassan IA, Varughese M, Kristiansson B. Henna causes life threatening haemolysis in glucose-6-phosphate dehydrogenase deficiency. Arch Dis Child 2001;85(5):411-412.

24. Vassileva S, Hristakieva E. Medical applications of tattooing. Clin Dermatol 2007;25(4):367-374. https://doi.org/10.1016/.j.clindermatol.2007.05.014

25. Kluger N, Aldasouqi S. A new purpose for tattoos: Medical alert tattoos. Presse Med 2013;42(2):134-137. https://doi.org/10.1016/j.lpm.2012.04.009

26. Van der Velden EM, de Jong BD, van der Walle HB, Stolz E, Naafs B. Cosmetic tattooing as a treatment of port-wine stains. Int J Dermatol 1993;32(5):372-375

27. Kluger N, Aldasouqi S. Medical alert tattoos in minors should not be advocated. Eur J Pediatr 2013;172(8):1141. https://doi.org/10.1007/s00431-013-1994-7

28. Wolf EK, Laumann AE. The use of blood-type tattoos during the Cold War. J Am Acad Dermatol 2008;58(3):472-476. https://doi.org/10.1016/.j.jaad.2007.11.019

29. Birngruber CG, Gorner N, Ramsthaler HF. [On the value of tattoos for identifying unknown bodies - a retrospective study of forensic autopsy cases from Giessen, Germany]. Arch Krimino 2016;237(1-2):13-24

30. Byard RW. Tattoos: Forensic considerations. Forensic Sci Med Pathol 2013;9(4):534-542. https://doi org/10.1007/s12024-013-9476-9

31. Hauri U, Hohl C. Photostability and breakdown products of pigments currently used in tattoo inks. Curr Probl Dermatol 2015;48:164-169. https://doi.org/10.1159/000369225

32. Lopez M, Croley J, Murphy KD. Atypical mycobacterial infections of the upper extremity: Becoming more atypical? Hand (NY) 2017;12(2):188-192. https://doi.org/10.1177/1558944716642764

33. Mudedla S, Avendano EE, Raman G. Non-tuberculous mycobacterium skin infections after tattooing in healthy individuals: A systematic review of case reports. Dermatol Online J 2015;21(6).

34. Tohme RA, Holmberg SD. Transmission of hepatitis $\mathrm{C}$ virus infection through tattooing and piercing a critical review Clin If tect Dis 2012.54(8):1167-1178. https:/10iorg/10.1093/cid/cir991

35. Urbanus AT, van den Hoek A, Boonstra A, et al. People with multiple tattoos and/or piercings are not at increased risk for HBV or HCV in the Netherlands. PLoS ONE 2011;6(9):e24736. https://doi org/10.1371/journal.pone. 0024736

6. Laux P, Tralau T, Tentschert J, et al. A medical-toxicological view of tattooing. Lancet 2016;387(10016):395402. https://doi.org/10.1016/S0140-6736(15)60215-X

37. Serup J, Hutton Carlsen K. Patch test study of 90 patients with tattoo reactions: Negative outcome of allergy patch test to baseline batteries and culprit inks suggests allergen(s) are generated in the skin through haptenization. Contact Dermatitis 2014;71(5):255-263. https://doi.org/10.1111/cod.12271

38. Kluger N. Cutaneous complications related to tattoos: 31 cases from Finland. Dermatology 2017;233(1):100-109. https://doi.org/10.1159/000468536

39. Sepehri M, Hutton Carlsen K, Serup J. Papulo-nodular reactions in black tattoos as markers of sarcoidosis: Study of 92 tattoo reactions from a hospital material. Dermatology 2016;232(6):679-686 https://doi.org/10.1159/000453315

40. Balci S, Sari E, Mutlu B. Comparison of risk-taking behaviour and frequency of piercing and tattooing among university students. J Pak Med Assoc 2015;65(6):587-592.

41. Zrno M, Frencl M, Degmecic D, Pozgain I. Emotional profile and risk behaviours among tattooed and non-tattooed students. Med Glas (Zenica) 2015;12(1):93-98.

42. Liao PA, Chang HH, Su YJ. Is tattooing a risk factor for adolescents' criminal behavior? Empirical evidence from an administrative data set of juvenile detainees in Taiwan. Risk Anal 2014;34(12):20802088. https://doi.org/10.1111/risa.12232

43. Carson HJ. The medium, not the message. How tattoos correlate with early mortality. Am J Clin Pathol 2014;142(1):99-103. https://doi.org/10.1309/ajcpdoi32fwqlueo

44. Musambira GW, Raymond L, Hastings SO. A comparison of college students' perceptions of older and younger tattooed women. J Women Aging 2016;28(1):9-23. https://doi.org/10.1080/08952841.2 014.950894

45. Swami V, Gaughan H, Tran US, Kuhlmann T, Stieger S, Voracek M. Are tattooed adults really more aggressive and rebellious than those without tattoos? Body Image 2015;15:149-152. https://doi. org/10.1016/j.bodyim.2015.09.001

46. Kluger $\mathrm{N}$. The risks of do-it-yourself and over-the-counter devices for tattoo removal. Int J Dermatol 2015;54(1):13-18. https://doi.org/10.1111/ijd.12613

47. Pinedo M, Burgos JL, Ojeda AV, FitzGerald D, Ojeda VD. The role of visual markers in police victimization among structurally vulnerable persons in Tijuana, Mexico. Int J Drug Policy 2015;26(5):501 508. https://doi.org/10.1016/j.drugpo.2014.08.019

48. Byard RW, Charlwood C. Commemorative tattoos as markers for anniversary reactions and suicide. J Forensic Leg Med 2014;24:15-17. https://doi.org/10.1016/j.jlm.2014.02.010

49. Breuner CC, Levine DA, the Committee on Adolescence. Adolescent and young adult tattooing piercing, and scarification. Pediatrics 2017;140(4). https://doi.org/10.1542/peds.2017-1962

50. Jonsson BH, Winzer R. What is hidden in tattoos? Am I Clin Pathol 2015;143(6):908-909.

51. Krezdorn N, Limbourg A, Paprottka FJ, Konneker, Ipaktchi R, Vogt PM. Assessing burn depth in tattooed burn lesions with LASCA imaging. Ann Burns Fire Disasters 2016;29(3):223-227.

52. Sarwar U, Javed M, Dickson WA. Diagnostic challenges of assessing the depth of burn injurie overlying intricate coloured tattoos. J Plast Reconstr Aesthet Surg 2014;67(7):e186-e187. https://doi org/10.1016/i.bjps.2014.01.03

53. Lo S, Grob M, Gilbert P, Dheansa B. Tattoos masquerading as full-thickness burns: Limitations of laser Doppler burns assessment. Plast Reconstr Surg 2006;117(2):716-717. https://doi.org/10.1097/01 prs.0000197910.66752.8d

54. Chenji S, Wilman AH, Mah D, Seres P, Genge A, Kalra S. Hair product artifact in magnetic resonance imaging. Magn Reson Imaging 2017;35:1-3. https://doi.org/10.1016/j.mri.2016.08.023

55. Noureddine Y, Bitz AK, Ladd ME, et al. Experience with magnetic resonance imaging of human subjects with passive implants and tattoos at 7 T: A retrospective study. MAGMA 2015;28(6):577-590. https://doi.org/10.1007/s10334-015-0499-y
56. Kluger N. [Tattoos and medical imaging: issues and myths]. Presse Med 2014;43(5):529-533. https:// doi.org/10.1016/j.lpm.2013.07.031

57. Ingenito T. Low level light therapy and tattoos: A case report. J Bodyw Mov Ther 2016;20(4):748-750. https://doi.org/10.1016/j.jbmt.2016.04.016

58. Vasold R, Naarmann N, Ulrich H, et al. Tattoo pigments are cleaved by laser light - the chemical analysis in vitro provides evidence for hazardous compounds. Photochem Photobiol 2004;80(2):18590. https://doi.org/10.1562/2004-05-17-ra-170

59. Schreiver I, Hutzler C, Laux P, Berlien HP, Luch A. Formation of highly toxic hydrogen cyanide upon ruby laser irradiation of the tattoo pigment phthalocyanine blue. Sci Rep 2015;5:12915. https://doi. org/10.1038/srep12915

60. Schreiver I, Luch A. At the dark end of the rainbow: Data gaps in tattoo toxicology. Arch Toxicol 2016;90(7):1763-1765. https://doi.org/10.1007/s00204-016-1740-9

61. Esteve Simo V, Martinez Carnovale L, Alvarez Rodriguez L, et al. Vascular access for hemodialysis and tattoos: A consideration to bear in mind. J Vasc Access 2017;18(5):e73. https://doi.org/10.5301/ jva. 5000703

62. Welliver D, Welliver M, Carroll T, James P. Lumbar epidural catheter placement in the presence of low back tattoos: A review of the safety concerns. AANA J 2010;78(3):197-201.

63. Sepehri M, Sejersen T, Qvortrup K, Lerche CM, Serup J. Tattoo pigments are observed in the Kupffer

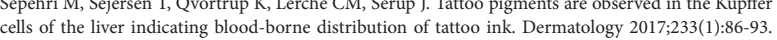
https://doi.org/10.1159/000468149

64. Blasco-Morente G, Perez-Lopez I, Martinez-Lopez A, et al. Pigmented lymph nodes in a patient with melanoma: Tattoos. J Eur Acad Dermatol Venereol 2016;30(11):e116-el17. https://doi.org/10.1111/ jdv. 13387

65. Kohler C, Foiato T, Marnitz S, et al. Potential surgical and oncologic consequences related to skin tattoos in the treatment of cervical cancer. J Minimum Invasive Gynecol 2016;23(7):1083-1087. https:// doi.org/10.1016/j.jmig.2016.07.016

66. Pinto A, Wieshmann H, Triantafyllou A, Shaw R. Tattoo-pigmented cervical lymph node that masqueraded as the sentinel lymph node in oral squamous cell carcinoma. Br J Oral Maxillofac Surg 2015;53(9):886-887. https://doi.org/10.1016/j.bjoms.2015.06.017

67. Luetkemeier MJ, Hanisko JM, Aho KM. Skin tattoos alter sweat rate and Na+ concentration. Med Sci Sports Exerc 2017;49(7):1432-1436. https://doi.org/10.1249/MSS.0000000000001244

68. Ross N, Farber M, Sahu J. Eruptive milia within a tattoo: A case report and review of the literature. J Drugs Dermatol 2017;16(6):621-624.

69. Kluger N, Koljonen V. Tattoos, inks, and cancer. Lancet Oncol 2012;13(4):e161-e168. https://doi, org/10.1016/S1470-2045(11)70340-0

70. Serup J, Carlsen KH, Sepehri M. Tattoo complaints and complications: Diagnosis and clinical spectrum. Curr Probl Dermatol 2015;48:48-60. https://doi.org/10.1159/000369645

71. Anthony E, Lun K, Godbolt A, McMeniman E. Diagnostic difficulties in skin cancer detection within attoos. Aust Fam Physician 2014;43(10):714-715

72. Korner R, Pfohler C, Vogt T, Muller CS. Histopathology of body art revisited - analysis and discussion of 19 cases. J Dtsch Dermatol Ges 2013;11(11):1073-1080. https://doi.org/10.1111/ddg.12178

73. Shinohara MM, Nguyen J, Gardner J, Rosenbach M, Elenitsas R. The histopathologic spectrum of decorative tattoo complications. J Cutan Pathol 2012;39(12):1110-1118. https://doi.org/10.1111/ cup. 12023

74. Latreille J, Levy JL, Guinot C. Decorative tattoos and reasons for their removal: A prospective study in 151 adults living in South of France. J Eur Acad Dermatol Venereol 2011;25(2):181-187. https://doi. org/10.1111/j.1468-3083.2010.03738.x

75. Koljonen V, Kluger N. Specifically requesting surgical tattoo removal: Are deep personal motivations involved? J Eur Acad Dermatol Venereol 2012;26(6):685-689. https://doi.org/10.1111/j.14683083.2011.04146.x

76. Armstrong ML, Roberts AE, Koch JR, Saunders JC, Owen DC, Anderson RR. Motivation for contemporary tattoo removal: A shift in identity. Arch Dermatol 2008;144(7):879-884. https://doi. org/10.1001/archderm.144.7.879

77. Armstrong ML, Stuppy DJ, Gabriel DC, Anderson RR. Motivation for tattoo removal. Arch Dermatol 996;132(4):412-416

78. Hutton Carlsen K, Serup J. Patients with tattoo reactions have reduced quality of life and suffer from itch: Dermatology life quality index and itch severity score measurements. Skin Res Technol 2015;21(1):101-107. https://doi.org/10.1111/srt.12164

79. Burris K, Kim K. Tattoo removal. Clin Dermatol 2007;25(4):388-392. https://doi.org/10.1016/j. clindermatol.2007.05.011

80. Koerber WA, jun., Price NM. Salabrasion of tattoos. A correlation of the clinical and histological results. Arch Dermatol 1978;114(6):884-888.

81. Shelley WB, Shelley ED. Focal salabrasion for removal of linear tattoos. J Dermatol Surg Oncol 1984;10(3):216-218

82. Peris Z. Removal of the 2002:10(1):15-19.

83. Wollina U, Kostler E. Tattoos: Surgical removal. Clin Dermatol 2007;5(4):393-397. https://doi.org/10.1016/i. clindermatol.2007.05.016

84. Kostler E. [Tattoos as a surgico-dermatological problem]. Dermatol Monatsschr 1982;168(1):1-9.

85. Zuber TJ. Fusiform excision. Am Fam Physician 2003;67(7):1539-1550.

86. Wheeler ES, Miller TA. Tattoo removal by split thickness tangential excision. West J Med 1976;124(4):272-275

87. Sepehri M, Jorgensen B, Serup J. Introduction of dermatome shaving as first line treatment of chronic tattoo reactions. J Dermatolog Treat 2015;26(5):451-455. https://doi.org/10.3109/09546634.2014.999021

88. Vecchione TR. Tattoo removal using precise shave excision and dermal overgrafting. Ann Plast Surg 1988;20(5):443-446

89. Elsaie ML, Nouri K, Vejjabhinanta V, et al. Topical imiquimod in conjunction with Nd:YAG laser for tattoo removal. Lasers Med Sci 2009;24(6):871-875. https://doi.org/10.1007/s10103-009-0709-9

90. Cozzi SJ, Le TT, Ogbourne SM, James C, Suhrbier A. Tattoo removal with ingenol mebutate. Clin Cosmet Investig Dermatol 2017;10:205-210. https://doi.org/10.2147/CCID.S135716

91. Goldman L, Wilson RG, Hornby P, Meyer RG. Radiation from a Q-switched ruby laser. Effect of repeated impacts of power output of 10 megawatts on a tattoo of man. J Invest Dermatol 1965;44:69-71.

92. Yules RB, Laub DR, Honey R, Vassiliadis A, Crowley L. The effect of Q-switched ruby laser radiation on dermal tattoo pigment in man. Arch Surg 1967;95(2):179-180.

93. Apfelberg DB, Maser MR, Lash H, White DN, Flores JT. Comparison of argon and carbon dioxide laser treatment of decorative tattoos: A preliminary report. Ann Plast Surg 1985;14(1):6-15 94. Kilmer SL, Anderson RR. Clinical use of the Q-switched ruby and the Q-switched Nd:YAG (1 $064 \mathrm{~nm}$
and $532 \mathrm{~nm}$ ) lasers for treatment of tattoos. J Dermatol Surg Oncol 1993;19(4):330-338.

5. Scheibner A, Kenny G, White W, Wheeland RG. A superior method of tattoo removal using the Q-switched ruby laser. J Dermatol Surg Oncol 1990;16(12):1091-1098

96. Reid WH, Miller ID, Murphy MJ, Paul JP, Evans JH. Q-switched ruby laser treatment of tattoos; a 9-year experience. Br J Plast Surg 1990;43(6):663-669.

97. Kilmer SL, Lee MS, Grevelink JM, Flotte TJ, Anderson RR. The Q-switched Nd:YAG laser effectively treats tattoos. A controlled, dose-response study. Arch Dermatol 1993;129(8):971-978.

9. Jones A, Roddey P, Orengo I, Rosen T. The Q-switched ND:YAG laser effectively treats tattoos in darkly pigmented skin. Dermatol Surg 1996;22(12):999-1001.

9. Shah G, Alster TS. Treatment of an amalgam tattoo with a Q-switched alexandrite $(755 \mathrm{~nm})$ laser. Dermatol Surg 2002;28(12):1180-1181 
100. Alster TS. Successful elimination of traumatic tattoos by the Q-switched alexandrite (755-nm) laser. Ann Plast Surg 1995;34(5):542-545.

101. Moreno-Arias GA, Camps-Fresneda A. The use of Q-switched alexandrite laser ( $755 \mathrm{~nm}, 100 \mathrm{~ns})$ for eyeliner tattoo removal. J Cutan Laser Ther 1999;1(2):113-115.
ent

102. Alster TS. Q-switched alexandrite laser treatment ( $755 \mathrm{~nm}$ ) of professional and amateur tattoos. J Am Acad Dermatol 1995;33(1):69-73.

103. Karsai S, Krieger G, Raulin C. Tattoo removal by non-professionals - medical and forensic considerations. J Eur Acad Dermatol Venereol 2010;24(7):756-762. https://doi.org/10.1111/j.1468-
colic considerations. J

104. Li Z, Zhang H, Li SH, Byard RW. Fatal phenol toxicity following attempted tattoo removal. J Forensic Sci 2016;61(4):1143-1145. https://doi.org/10.1111/1556-4029.13106

105. O'Brien SF, Xi G, Fan W, et al. Are donors in Canada compliant with deferral for tattoos and piercing? Blood Transfus 2014;12(1):141-142. https://doi.org/10.2450/2014.0233-13
106. South African National Blood Service and Western Province Blood Transfusion Service. Standards of practice for blood transfusion in South Africa. 2016. http://www.satiba.org.za/documents/resources/ practice for blood transfusion in South Africa. 2016. http://W
standards-for-blood-transfusion.pdf (accessed 3 August 2018)

107. South African Council for Piercing and Tattoo Professionals. Tattooing and body piercing: Guidelines for the prevention and control of infection. https://www.bodyartcouncil.co.za/Guidelines $\% 20$ for $\% 20$
for for the prevention and control of infection. https://www.bodyartcouncil.co.za/Guidelines\%20for\%
the $\% 20$ Prevention $\% 20$ and $\% 20$ Control\%20 of\% 20 Infection.pdf (accessed 17 November 2017).

the $\% 20$ Prevention $\% 20 \mathrm{and} \% 20$ Control\% 20 of $\% 20$ nfection.pdf (accessed 17 November 2017 ).
108. Serup J. Seamless prevention of adverse events from tattooing: integrated strategy emphasising the customer-tattooist interaction. Curr Probl Dermatol 2015;48:236-247. https://doi.org/10.1159/000370017 109. Sardana K, Ranjan R, Ghunawat S. Optimising laser tattoo removal. J Cutan Aesthet Surg 2015;8(1):16-24 https://doi.org/10.4103/0974-2077.155068

Accepted 3 April 2018 